\title{
Applying Case Definition Criteria to Irritable Bowel Syndrome
}

\author{
Steven H. Yale, MD; A. Kenneth Musana, MD; Amy Kieke, PhD; \\ Jennifer Hayes, MS; Ingrid Glurich, PhD; and Po-Huang Chyou, PhD
}

\begin{abstract}
Objective: The quality of documentation of signs and symptoms and validation of the diagnosis of irritable bowel syndrome (IBS) according to case definition criteria of Manning, Rome I and Rome II in an office setting has not been previously described. We sought to identify and validate cases of IBS based on the Manning, Rome I and Rome II diagnostic criteria in a rural practice setting.
\end{abstract}

Setting: Marshfield Epidemiologic Study Area (MESA) Central consisting of I4 ZIP codes in central Wisconsin, USA.

Methods: A retrospective cohort study involved 890 patients with the diagnostic codes 564 .I for irritable bowel syndrome and 306.4 spastic colon-psychogenic who had presented to the practice from 1993-2003. Duration, frequency, concordance and intensity of symptoms based on case definitions of IBS were abstracted from the medical records.

Results: During the study period, 890 incident cases of IBS were identified. Only 404 met one or more of the three diagnostic criteria, 340 (84\%) met only the Manning criteria, 35 (10\%) met only Manning and Rome I criteria, 4 (I\%) met both Manning and Rome II criteria, and 25 (6\%) met Manning and Rome I and Rome II criteria. Age adjusted incidence rates per 100,000 person-years for validated IBS cases during the observational period were 87 to 170 by Manning (lower confidence interval [Cl]:57I27, upper Cl: I 16-2 I3), 8 to 34 (lower Cl: 0-14, upper Cl: 16-53) for Rome I and 3 to 16 (lower $\mathrm{Cl}$ : 0-3, upper Cl: 8-28) for Rome II. Comparison of Rome I and Rome II showed moderate concordance (kappa statistic $=0.5 \mathrm{I} ; 95 \% \mathrm{Cl}: 0.39-0.64)$.

Conclusions: Only a small percentage of IBS cases with assigned diagnostic codes met case definition criteria for IBS. There were low concordance rates among the three diagnostic criteria applied.

Keywords: Case definition; Irritable bowel syndrome; Abdominal pain

I

rritable bowel syndrome (IBS) is a functional disorder of the gastrointestinal tract characterized by recurrent episodes of abdominal pain or discomfort along with changes in frequency or consistency of the stool in the absence of an organic etiology. The condition is heterogeneous, exhibiting variability in the frequency of symptoms reported within and between males and females. ${ }^{1}$

The pathophysiological mechanisms of IBS are not completely understood. Alterations in gut motility, visceral perception, and central processing of pain and motor function due to abnormalities in the enteric and central

Reprint Requests: Steven H. Yale, MD, Clinical Research Center, Marshfield Clinic Research Foundation, 1000 North Oak Avenue, Marshfield, WI 54449. Tel: 7I5-387-9I 10, Fax: 7I5-389-3808, Email: yale.steven@mcrf.mfldclin.edu.

nervous system are believed to account for symptoms of IBS. ${ }^{2}$ The brain-gut axis and biopsychosocial model have been used to explain how intrinsic and extrinsic stimuli modulate disease expression. ${ }^{3,4}$ It is unknown whether IBS is primarily a disorder of abnormal perception to a normal stimulus, or a disorder of normal perception to an abnormal physiologic sensory stimulus. Since no structural abnormalities or biochemical markers characterize IBS, diagnosis is based on the presence of clinical symptoms. ${ }^{2}$ Symptom-based diagnostic criteria have been established to create uniformity in reporting and enhance diagnostic accuracy.

Received: January 2, 2008

Revised: March 21, 2008

Accepted: March 26, 2008
Presented in part at the Society of General Internal Medicine Midwest Chapter Annual Meeting, September 2006, Chicago, IL, USA.

doi: $10.3|2| / \mathrm{cmr} .2008 .788$ 
Table 1. Manning, Rome I and Rome II criteria.

\section{Manning Criteria}

1. Visible abdominal distention

2. Pain relieved with a bowel action

3. More frequent stools with onset of pain

4. Looser stools with the onset of pain

5. Rectal passage of mucus

6. Sense of incomplete evacuation

\section{Rome I}

At least 3 months of continous or recurrent symptoms:

1. Abdominal pain or discomfort that is:

$\square$ Relieved with defecation And/or

Associated with a change in frequency of stool And/or

Associated with a change in consistency of stool Plus

2. Two or more of the following, on at least one-fourth of occasions or days:

Altered stool frequency (for research purposes, "altered" may be defined as more than three bowel movements each day or fewer than three bowel movements each week)

- Altered stool form (lumpy and hard, or loose and watery)

- Altered stool passage (straining, urgency, or a feeling of incomplete evacuation)

$\square$ Passage of mucus

B Bloating or feeling of abdominal distention

\section{Rome II}

Abdominal distention or pain of at least 12 weeks duration (not necessarily consecutive weeks) in the preceding 12 months accompanied by two of the following three features of altered bowel habits:

- Relieved with defecation

An onset associated with change in the frequency of stool

An onset associated with change in the form (appearance) of stool
All diagnostic criteria used to differentiate IBS from organic diseases are self-reported measures of abdominal pain and bowel habits (table 1). ${ }^{5-8}$ The diagnosis of IBS is confirmed by applying symptom-based criteria and pursuing further diagnostic evaluations to exclude organic diseases, as needed. Symptom-based criteria should be individualized, taking into account the patient's age, associated conditions, duration of symptoms, previous diagnostic evaluations, severity of symptoms, travel history and lactose consumption.

Criteria used to establish the diagnosis of IBS have evolved since the initial work of Manning et $\mathrm{al}^{5}$ in 1978 and reflect a better understanding of the symptomatology associated with this disease. The Rome I and II criteria reflect more specific clinical diagnostic standards than the Manning criteria. ${ }^{9}$ Thus, many patients previously diagnosed with IBS under the Manning criteria would not receive a diagnosis of IBS based on the most recent Rome criteria. However, if the more restrictive case definitions of the Rome I and II criteria are applied, patients with IBS may potentially be underdiagnosed. ${ }^{10,11}$ Previous studies evaluating case definitions were based on surveys and are limited by the diagnostic criteria used, the questions asked and the ethnicity and cultural background of the population sampled. ${ }^{9,10,12}$

In this retrospective study, we utilized data from medical records to evaluate the diagnosis of IBS in a population-based cohort within a clinical practice. The quality of medical record documentation of clinical symptoms of IBS was determined, and IBS diagnoses were validated based on the Manning, Rome I and Rome II criteria. These three alternative criteria used to diagnose IBS were compared in terms of biennial age- and gender-adjusted incidence rates beginning from January 1, 1993 through December 31, 2003 per 100,000 person-years. Percent concordance of each paired comparison of criteria-based IBS was also determined.

\section{Methods}

Setting

The central region of the Marshfield Epidemiologic Study Area (MESA) is a select geographic region of 14 ZIP codes in central Wisconsin where nearly all of the approximately 60,000 residents receive their medical care from Marshfield Clinic and affiliated hospitals. The city of Marshfield represents the approximate center of MESA Central and is home to 18,900 residents. Marshfield is the only community in MESA with a population greater than 4,000. The remainder of the MESA Central population lives in areas designated as "rural," as defined by the Federal Office of Management and Budget. According to the 2000 United States Census, the population residing in MESA Central was 97\% nonHispanic, white.

MESA validation studies have shown that over a third of the people moving out of the study area stay within Marshfield Clinic's broader service area and continue to obtain care from 
Marshfield Clinic. The population of MESA is quite stable, with approximately $3 \%$ of the original 1991 cohort lost to outmigration annually. The MESA database stores current information regarding name, sex, date of birth, date of death, and current and past addresses of each resident. Information in the database can also be linked to Marshfield Clinic's extensive electronic medical record. Recent validation efforts confirmed that the MESA database comprehensively captures patients' hospital discharges and deaths, as well as $92 \%$ of all medical outpatient visits of MESA Central residents. ${ }^{13}$

\section{Case Definition}

Incident cases were defined as (1) those receiving International Classification of Diseases (ICD)-9 codes 564.1 (irritable bowel syndrome) or 306.4 (spastic colonpsychogenic) with no prior history of the codes, and (2) those with documentation of a diagnosis of IBS. Validation of incident cases of IBS was based on abstraction of clinicians' notes in the electronic medical record on the reference date when the ICD-9 code was assigned. Definitive cases confirmed by symptomology included those who met Manning, Rome I or Rome II diagnostic criteria for IBS, with documentation in the medical record of the term 'IBS.'

\section{Inclusion Criteria}

Patients were included in this study if they were $\geq 18$ years of age and resided in MESA Central at the time of their initial diagnosis of IBS during odd-numbered years from January 1, 1993 through December 31, 2003. Odd-numbered years were chosen to maximize the study interval surveyed, within the constraints of funding available. Patients were excluded if diagnosed with an organic disease that was associated with similar symptoms (e.g., Crohn's disease, ulcerative colitis, celiac sprue or colon cancer) within 12 months of the IBS diagnosis.

\section{Chart Abstraction}

Medical records of Marshfield Clinic patients initially diagnosed with IBS were retrospectively reviewed to validate the diagnosis of IBS made at the time the ICD-9 code for IBS was assigned (reference date). Data abstracted included the date of initial diagnosis of IBS, symptoms 12 months prior to the reference date, laboratory and procedural information 12 months prior to the reference date and diagnoses made 12 months after the first diagnosis of IBS to determine whether there was any change to an alternative diagnosis. Demographic characteristics (i.e., age and gender), specialties of the physicians making the diagnoses, dates of last clinical follow-up with symptoms of IBS, referrals to a gastroenterologist within 3 months of first diagnosis of IBS, and bowel patterns (e.g., constipation, diarrhea, alternating diarrhea and constipation) were also abstracted. Duration, frequency and/or intensity of symptoms of diarrhea, abdominal pain, cramping, discomfort, distention, bloating, constipation, change in stool habits, pain relief with defecation, stool frequency (i.e., $\geq 3$ or $<3$ bowel movements/day, $\geq 3$ or $<3$ bowel movements/week), stool characteristics (e.g., lumpy, hard, watery, loose, with and without pain, presence of mucus), incomplete evacuation, straining and urgency were ascertained. The duration of symptoms was recorded to ensure that they met the duration criteria specified in the Rome I and II criteria. Quality assurance procedures included an independent re-abstraction of a $10 \%$ sample of all charts to validate the accuracy of the abstraction.

\section{Statistical Methods}

Abstracted data were used to subset each of the phenotypic groupings, but no statistical tests were performed due to case overlap among the groups. Biennial age- and genderadjusted incidence rates per 100,000 person-years and corresponding 95\% upper and lower confidence intervals (CI) were calculated for validated, definitive cases based on each diagnostic criterion. The percent of concordance for paired comparisons among Manning and Rome criteria was assessed based on kappa values with 95\% CI (Kappa values $<0=$ poor agreement, $0.0-0.20=$ slight agreement, $0.21-0.40=$ fair agreement, 0.41-0.60 = moderate agreement, $0.61-0.80=$ substantial agreement and 0.81-1.0 $=$ almost perfect agreement). ${ }^{14}$ For confirmed cases, McNemar tests were performed to assess percent of concordance for paired comparisons among IBS criteriabased classifications.

\section{Results}

During the study period, 890 incident cases of IBS were electronically identified using ICD-9 codes 564.1 and 306.40. Electronic review confirmed 599 cases (67\%), 157 (18\%) were incorrectly coded, and $134(15 \%)$ had a past history of IBS (figure 1). Of the 599 confirmed IBS cases, 13 (2\%) were later reclassified with alternative diagnoses (e.g., Crohn's disease or diverticulitis) and excluded, leaving 586 confirmed cases. The majority $(70 \%)$ of the confirmed incident cases were females (mean age $=43$ years, range 18-101). Most $(89 \%)$ diagnoses of IBS were made by nongastroenterologists.

When the Manning, Rome I and Rome II diagnostic criteria for IBS were applied to the 586 confirmed cases, only 404 met one or more of the three diagnostic criteria. No patients in this study presented with symptomology that fulfilled Rome I or II criteria alone. Sixty patients meeting Rome I criteria also met Manning and/or Rome II criteria, and 29 patients meeting Rome II criteria also met those of Manning and/or Rome I. There was overlap of symptoms among the 404 patients meeting Manning criteria with 35 (9\%) meeting Manning and Rome I and 4 (1\%) meeting Manning and Rome II criteria (figure 2).

\section{IBS Symptoms}

IBS symptoms were documented in the medical records within 12 months prior to the reference date for diagnosis in $573(98 \%)$ patients. Among the 404 incident cases who satisfied one or more diagnostic criteria, the most commonly 


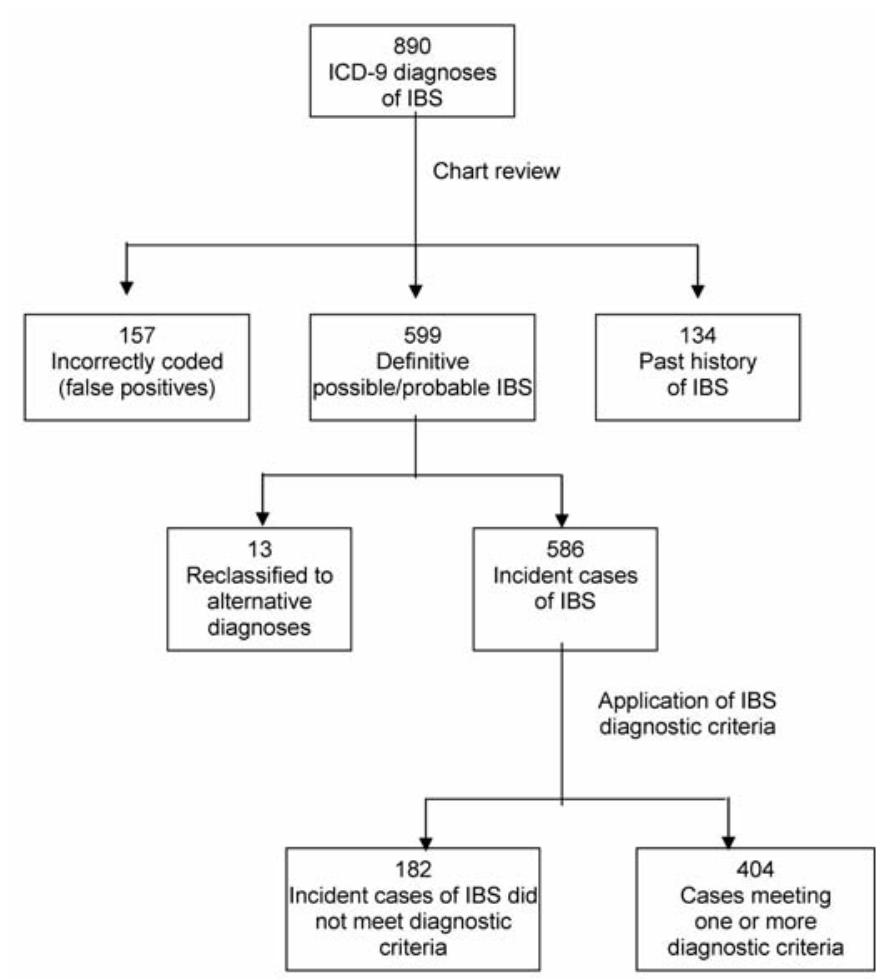

Figure 1. Selection of cases based on clinicians' documentation in the medical record and validation by the IBS diagnostic criteria.

reported symptoms included abdominal discomfort (i.e., pain and cramping) in 290 (71\%), loose or watery stools in 200 $(50 \%)$ and abdominal bloating or distention in 217 (54\%).

\section{Incidence Rate of IBS}

Biennial age-adjusted/gender-specific incident rates in males and females for definitive diagnoses of IBS beginning in 1993 through 2003 per 100,000 person-years for the Manning, Rome I and Rome II are shown in table 2 and figures 3-5. Age adjusted incidence rates per 100,000 person-years for validated IBS cases during the observational period were 87170 by Manning (lower CI: 57-127, upper CI: 116-213), 8-34 (lower CI: 0-14, upper CI: 16-53) for Rome I and 3-16 (lower CI: 0-3, upper CI: 8-28) for Rome II. We also found that the gender-specific incident rate for new cases of IBS meeting the Manning criteria between 1993 to 2003 was higher for females (113 to 197 per 100,000 person-years) than for males (46 to 141 per 100,000 person-years). There was, however, considerable overlap in the CIs during some years (not shown).

\section{Concordance}

Concordance based on kappa and proportion methods was calculated for IBS cases satisfying Manning or Rome I or Rome II criteria. The concordance between Rome I and Rome II criteria was moderate (kappa value of 0.51 ; 95\% CI: 0.39-0.64). Of 404 subjects with confirmed IBS, 25 met Rome I and II criteria while 340 patients did not, 39 met Manning and Rome I criteria, whereas only four met criteria for Manning and Rome II.

\section{Discussion}

We evaluated the medical records of 890 patients with ICD-9 diagnoses of IBS within the MESA Central area to determine the validity of the diagnoses on application of Manning, Rome I and Rome II diagnostic criteria. An incident case was defined as (1) a patient with a first time diagnosis of IBS based on ICD-9 codes for IBS or spastic colon, and (2) documentation of the terms 'possible,' 'probable,' or 'definitive' IBS. Of 890 cases, incident IBS was validated in 586 (66\%) patients. Some cases were excluded due to a past history of IBS or inaccurate entries of the codes on the reference dates.

Case definition criteria based on documented clinical symptoms identified 404 patients who met one or more of the diagnostic criteria. Consistent with findings of previous studies, the initial IBS diagnosis was made primarily by primary care physicians. ${ }^{15}$ The fact that only $404 / 890$ cases $(45 \%)$ met one or more of the diagnostic criteria suggests that primary care physicians may not be aware of the Manning or Rome criteria, fail to recognize or inquire about the symptoms associated with the diagnostic criteria, do not appropriately utilize the diagnostic criteria, or the diagnostic criteria have limitations relative to clinical application. ${ }^{15-18}$

Unlike the Manning criteria, the Rome I and II criteria include a specification regarding the percentage of time that symptoms need to be present. Thus, Rome I and II criteria are more conservative and less inclusive compared to the Manning criteria. Furthermore, Rome II criteria appeared more restrictive than the Rome I criteria despite the simplicity of their design. On assessing utility of Rome I and II criteria, Chey et $\mathrm{al}^{11}$ found that Rome I criteria had higher sensitivity compared to Rome II for the diagnosis of IBS. Thus, patients diagnosed with IBS using Rome I may not fulfill the Rome II criteria. ${ }^{19}$ In the general population, the Rome I and II criteria identify similar proportions of persons with IBS. However, in

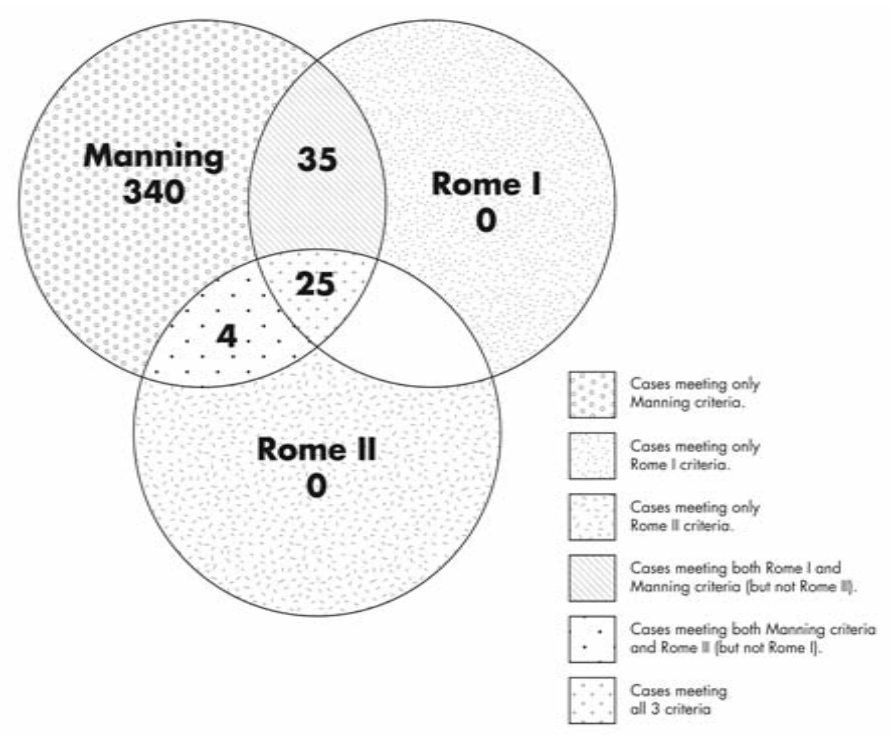

Figure 2. Frequency and overlap of IBS cases based on the Manning, Rome I, and Rome II diagnostic criteria. 
Table 2. Age-adjusted incidence rates and $95 \%$ confidence intervals for definitive, validated IBS cases per 100,000 person-years.

\begin{tabular}{lccccc}
\hline Criteria & Year & Total Count & Total Rate & Lower Cl & Upper CI \\
IBS - ICD9 code & 1993 & 54 & 161.07 & 117.19 & 204.95 \\
IBS - ICD9 code & 1995 & 91 & 249.16 & 197.37 & 300.95 \\
IBS - ICD9 code & 1997 & 72 & 191.68 & 147.05 & 236.30 \\
IBS - ICD9 code & 1999 & 67 & 173.97 & 132.09 & 215.84 \\
IBS - ICD9 code & 2001 & 66 & 167.28 & 126.65 & 207.91 \\
IBS - ICD9 code & 2003 & 51 & 130.53 & 94.51 & 166.54 \\
IBS - Manning criteria & 1993 & 36 & 103.26 & 68.84 & 137.67 \\
IBS - Manning criteria & 1995 & 62 & 170.11 & 127.23 & 212.98 \\
IBS - Manning criteria & 1997 & 47 & 124.14 & 88.40 & 159.86 \\
IBS - Manning criteria & 1999 & 41 & 105.42 & 72.99 & 137.84 \\
IBS - Manning criteria & 2001 & 48 & 122.42 & 87.58 & 157.25 \\
IBS - Manning criteria & 2003 & 34 & 86.53 & 57.28 & 115.78 \\
IBS - Rome I criteria & 1993 & 5 & 15.18 & 1.567 & 28.79 \\
IBS - Rome I criteria & 1995 & 12 & 33.61 & 14.294 & 52.93 \\
IBS - Rome I criteria & 1997 & 8 & 20.02 & 6.106 & 33.93 \\
IBS - Rome I criteria & 1999 & 8 & 19.99 & 6.066 & 33.92 \\
IBS - Rome I criteria & 2001 & 9 & 22.69 & 7.775 & 37.60 \\
IBS - Rome I criteria & 2003 & 3 & 7.51 & 0 & 16.01 \\
IBS - Rome II criteria & 1993 & 2 & 6.86 & 0 & 16.37 \\
IBS - Rome II criteria & 1995 & 6 & 15.55 & 2.93 & 28.18 \\
IBS - Rome II criteria & 1997 & 4 & 9.77 & 0.18 & 19.36 \\
IBS - Rome II criteria & 1999 & 4 & 9.82 & 0.175 & 19.47 \\
IBS - Rome II criteria & 2001 & 1 & 2.60 & 0 & 7.70 \\
IBS - Rome II criteria & 2003 & 3 & 7.94 & 0 & 16.95 \\
\hline
\end{tabular}

$\mathrm{CI}$, confidence interval; IBS, irritable bowel syndrome; ICD9, International Classification of Diseases.

a clinical setting, the Rome II criteria identify a smaller number of patients compared to the Rome I criteria. ${ }^{2,9,18}$ The fact that no patients in this study fulfilled Rome I and II criteria alone may relate to their original design as epidemiological screening tools for identifying patients meeting clinical trial eligibility requirements. ${ }^{4}$ Hence, their applicability as clinical practice-based tools for evaluating IBS may be limited. ${ }^{19,20}$

In follow-up studies, the Rome and Manning criteria have been associated with accurate IBS diagnoses. Once the diagnosis is confirmed by either Manning or Rome criteria and limited investigations are negative, diagnostic reclassification seldom occurs. ${ }^{18,21,22}$ Our results confirmed this finding: only 13 initial diagnoses were reclassified over the 12 month observational period.

We reported the rate of clinical diagnosis as a surrogate for true incidence. True incidence of IBS could not be accurately ascertained due to the clinical nature of this study, and we postulated that the more severe cases of IBS who sought medical care were those captured in the present study. Furthermore, Rome II criteria were designed to define a more homogenous population, and therefore, likely underestimate the incidence of IBS. 19

Age- and gender-adjusted biennial incidence rates for definitive cases of IBS were reported between 1993 and 2003.
Historically, incidence data derived from patient office visits ranged from 196 to 250 cases per 100,000 person-years. ${ }^{20,23}$ We found a similar crude incidence rate of 128 to 250 (CI lower: 93-199, upper: 163-302) based on symptomology documented in the medical record for odd numbered years, with lower rates based on specific diagnostic criteria. Population-based surveys project that approximately $9 \%$ of the general population will have an onset of IBS symptoms over a 1-year period. ${ }^{24}$ Overall, when persons with any previous symptoms are excluded, the true incidence rate probably ranges from $1 \%$ to $2 \% .25$

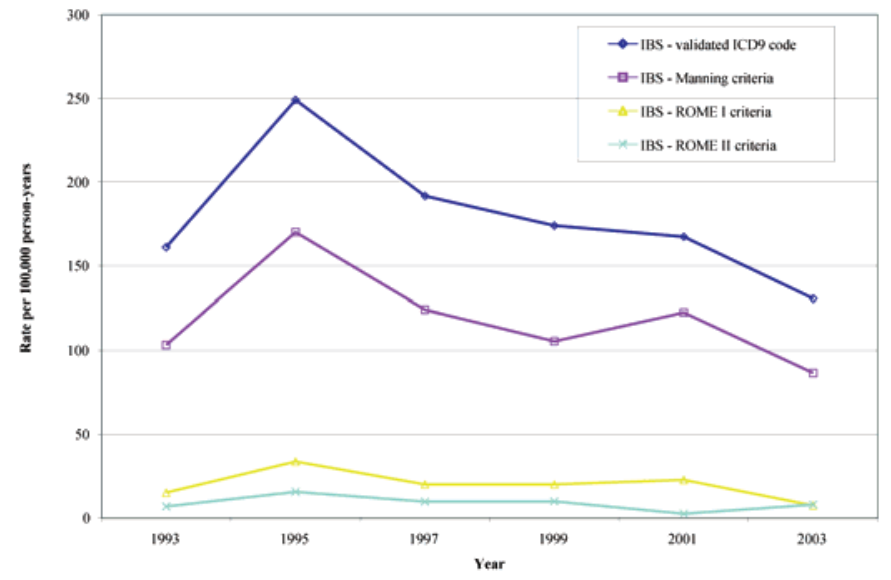

Figure 3. Age-adjusted incidence rate of validated definitive IBS diagnoses. 


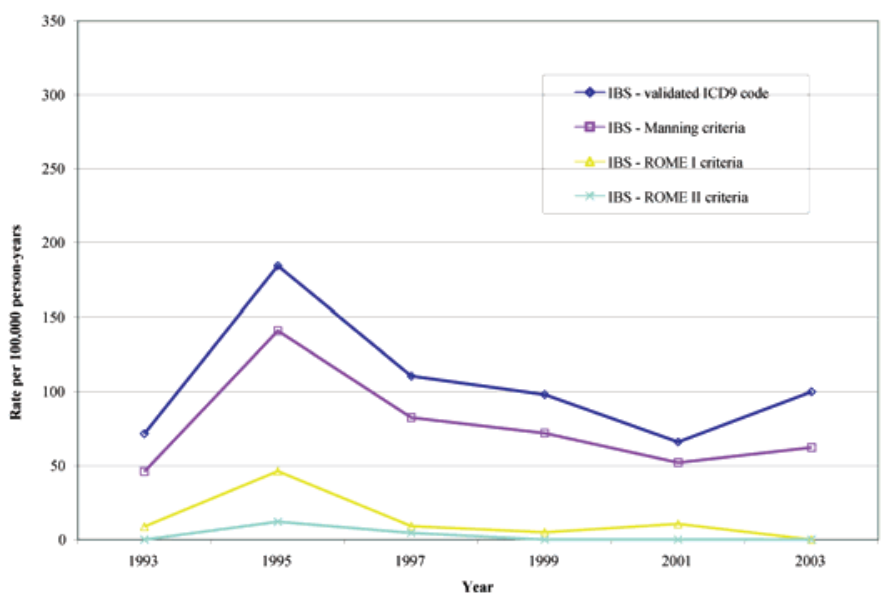

Figure 4. Age-adjusted incidence rate of validated definitive IBS diagnoses in males.

Unlike previous studies that have reported female-to-male ratios as high as 3:1, our study documented a ratio of femalesto-males of approximately $2: 1$, respectively. ${ }^{26-28} \mathrm{We}$ did not explore, and it remains unknown, why a gender-related difference exists in Western societies. Possible explanations include that women more commonly seek medical care by physicians than do men, or that there is a cultural or genderrelated susceptibility to this disease..$^{29}$

Population-based surveys have reported divergent concordance rates between the diagnostic criteria. A population-based survey on functional gastrointestinal disorders in Canada assessed the validity of Rome I and II criteria. They reported that $74.8 \%$ of persons diagnosed with IBS by Rome I criteria were also diagnosed by Rome II criteria. Conversely, $83.5 \%$ of persons diagnosed with IBS by Rome II were diagnosed by Rome I criteria (kappa 0.76). ${ }^{30}$ Our study revealed low concordance rates between Manning, Rome I and Rome II criteria. Similarly, Mearin et al ${ }^{10}$ found low concordance rates between Manning and Rome I criteria (15.2\%) and Manning and Rome II criteria (1.1\%) in a population-based survey. Chey et al ${ }^{11}$ reported $47 \%$ agreement among patients fulfilling Rome I and II criteria. The low concordance rates are likely the result of methodological differences, such as differing case definitions (e.g., absence of pain in the Manning criteria); differing definitions of stool frequency, form and urgency; differing specifications by Rome I and II criteria for a frequency $\geq 25 \%$; and more restrictive case definition requirements for Rome I and II criteria that may contribute to the variable identification of persons with the disorder. ${ }^{9,31-33}$

We were not able to determine period prevalence estimates in our population, since our validation efforts of the oddnumbered years indicated that we could not rely on the ICD9 codes for a definitive IBS diagnosis and available funds did not allow us to validate ICD-9 code data prior to January 1, 1993 or during even-numbered years. We also recognize the limited accuracy of the ICD-9 codes for identifying patients with a definitive diagnosis of IBS based on case definition criteria, which further limited our ability to determine prevalence since IBS is a heterogeneous condition whose diagnosis relies on documentation of symptoms. The retrospective design of our study would likely cause incidence estimates to underestimate the true MESA incidence of IBS due to potential inaccuracies in the documentation of symptoms in the medical record or lack of ICD-9 code assignment to potentially positive IBS cases. A major strength of this study was that it was population-based and independent of self-administered questionnaires to define IBS. The extent of population coverage and health information captured using a resource, such as the MESA database, minimizes reporting and referral bias. However, limiting the study to the MESA population of which $97 \%$ are Caucasian poses obvious limitations on the generalizability of the findings.

In conclusion, the diagnosis of irritable bowel syndrome (IBS) is currently based on symptomatic criteria that exclude other conditions affecting the gastrointestinal tract, such as celiac disease, food allergies, and infections. The absence of appropriate diagnostic and therapeutic approaches for IBS places a significant burden on the patient and the health care system due to direct and indirect costs of care. ${ }^{34-36}$ Symptomatic criteria are often used inappropriately and are limited to specific populations. The absence of alarm symptoms (e.g. unintentional weight loss, rectal bleeding) in patients who meet diagnostic criteria may not necessitate routinely ordering further laboratory tests or pursuing further diagnostic evaluation. ${ }^{36,37}$ Our study demonstrated that only a small percentage $(45 \%)$ of IBS-coded diagnoses actually met the case definition for IBS. Reasons underlying this could include poor documentation of symptoms, absence of symptoms, or failure of clinicians to inquire about symptoms. A low concordance rate between the three diagnostic criteria was further observed and was likely attributable to the more restrictive Rome I and II criteria.

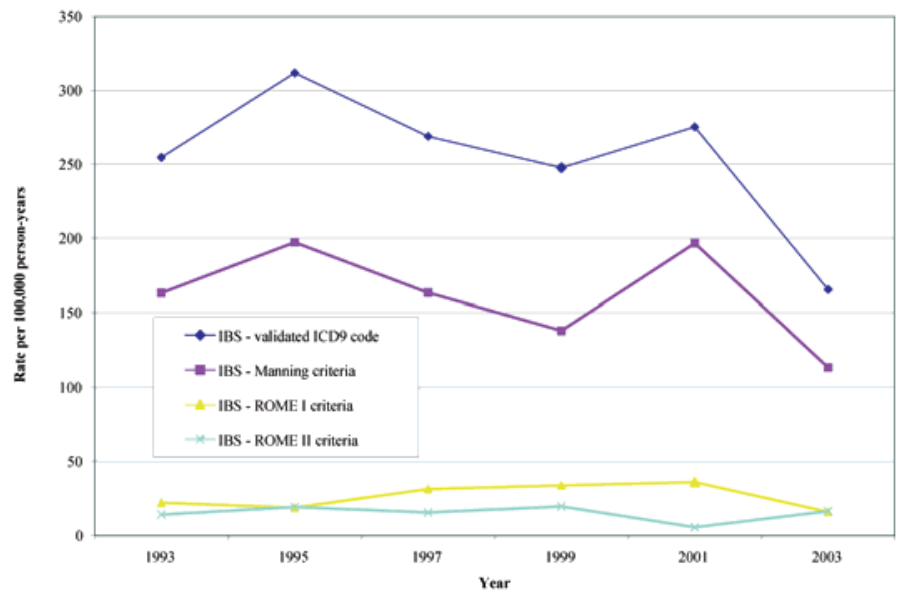

Figure 5. Age-adjusted incidence rate of validated definitive IBS diagnoses in females. 


\section{Acknowledgments}

The authors thank Marshfield Clinic Research Foundation for its support through the services of Linda Weis and Alice Stargardt in the preparation of this manuscript.

\section{References}

1. Smith RC, Greenbaum DS, Vancouver JB, Henry RC, Reinhart MA, Greenbaum RB, Dean HA, Mayle JE. Gender differences in Manning criteria in the irritable bowel syndrome. Gastroenterology 1991;100:591-595.

2. Camilleri M, Heading RC, Thompson WG. Clinical perspectives, mechanisms, diagnosis and management of irritable bowel syndrome. Aliment Pharmacol Ther 2002;16:1407-1430.

3. Ringel Y, Sperber AD, Drossman DA. Irritable bowel syndrome. Annu Rev Med 2001;52:319-338.

4. Drossman DA. The Rome criteria process: diagnosis and legitimization of irritable bowel syndrome. Am J Gastroenterol 1999;94:2803-2807.

5. Manning AP, Thompson WG, Heaton KW, Morris AF. Towards positive diagnosis of the irritable bowel. Br Med J 1978;2:653-654.

6. Thompson W, Creed F, Drossman D, Heaton K, Mazzacca G. Functional bowel disorders and chronic functional abdominal pain. Gastroenterol Int 1992;5:75-91.

7. Thompson WG, Longstreth GF, Drossman DA, Heaton KW, Irvine EJ, Muller-Lissner SA. Functional bowel disorders and functional abdominal pain. Gut 1999;45:II43-II47.

8. Thompson WG, Dotewall G, Drossman DA, Heaton KW, Kruis W. Irritable bowel syndrome: guidelines for the diagnosis. Gastroenterol Int 1989;2:92-95.

9. Boyce PM, Koloski NA, Talley NJ. Irritable bowel syndrome according to varying diagnostic criteria: are the new Rome II criteria unnecessarily restrictive for research and practice? Am J Gastroenterol 2000;95:3176-3183.

10. Mearin F, Badia X, Balboa A, Baro E, Caldwell E, Cucala M, Diaz-Rubio M, Fueyo A, Ponce J, Roset M, Talley NJ. Irritable bowel syndrome prevalence varies enormously depending on the employed diagnostic criteria: comparison of Rome II versus previous criteria in a general population. Scand J Gastroenterol 2001;36:1155-1161

11. Chey WD, Olden K, Carter E, Boyle J, Drossman D, Chang L. Utility of the Rome I and Rome II criteria for irritable bowel syndrome in U.S. women. Am J Gastroenterol 2002; 97:2803-2811

12. Saito YA, Locke GR, Talley NJ, Zinsmeister AR, Fett SL, Melton LJ 3rd. A comparison of the Rome and Manning criteria for case identification in epidemiological investigations of irritable bowel syndrome. Am J Gastroenterol 2000;95:2816-2824.

13. DeStefano F, Eaker ED, Broste SK, Nordstrom DL, Peissig PL, Vierkant RA, Konitzer KA, Gruber RL, Layde PM. Epidemiologic research in an integrated regional medical care system: the Marshfield Epidemiologic Study Area. J Clin Epidemiol 1996;49:643-652.

14. Landis JR, Koch GG. The measurement of observer agreement for categorical data. Biometrics 1977;33:159-174.

15. Thompson WG, Heaton KW, Smyth GT, Smyth C. Irritable bowel syndrome in general practice: prevalence, characteristics, and referral. Gut 2000;46:78-82.

16. Thompson WG, Heaton KW, Smyth GT, Smyth C. Irritable bowel syndrome: the view from general practice. Eur J Gastroenterol Hepatol 1997;9:689-692.

17. Longstreth GF, Burchette RJ. Family practitioners' attitudes and knowledge about irritable bowel syndrome: effect of a trial of physician education. Fam Pract 2003;20:670-674.
18. Vanner SJ, Depew WT, Paterson WG, DaCosta LR, Groll AG, Simon JB, Djurfeldt M. Predictive value of the Rome criteria for diagnosing the irritable bowel syndrome. Am J Gastroenterol 1999;94:2912-2917.

19. Cash BD, Chey WD. Diagnosis of irritable bowel syndrome. Gastroenterol Clin North Am 2005;34:205-220, vi.

20. Garcia Rodriguez LA, Ruigomez A, Wallander MA, Johansson S, Olbe L. Detection of colorectal tumor and inflammatory bowel disease during follow-up of patients with initial diagnosis of irritable bowel syndrome. Scand J Gastroenterol 2000;35:306-311.

21. Harvey RF, Mauad EC, Brown AM. Prognosis in the irritable bowel syndrome: a 5-year prospective study. Lancet 1987; 1:963-965

22. Adeniji OA, Barnett CB, Di Palma JA. Durability of the diagnosis of irritable bowel syndrome based on clinical criteria. Dig Dis Sci 2004;49:572-574.

23. Locke GR 3rd. Natural history of irritable bowel syndrome and durability of the diagnosis. Rev Gastroenterol Disord 2003;3:S12-S17.

24. Talley NJ, Weaver AL, Zinsmeister AR, Melton LJ. Onset and disappearance of gastrointestinal symptoms and functional gastrointestinal disorders. Am J Epidemiol 1992;136:165177.

25. Agreus L, Svardsudd K, Nyren O, Tibblin G. Irritable bowel syndrome and dyspepsia in the general population: overlap and lack of stability over time. Gastroenterology 1995;109:671-680.

26. Heaton KW, O'Donnell LJ, Braddon FE, Mountford RA, Hughes AO, Cripps PJ. Symptoms of irritable bowel syndrome in a British urban community: consulters and nonconsulters. Gastroenterology 1992;102:1962-1967.

27. Drossman DA, Li Z, Andruzzi E, Temple RD, Talley NJ, Thompson WG, Whitehead WE, Janssens J, Funch-Jensen P, Corazziari E, Richter JE, Koch GG. U.S. householder survey of functional gastrointestinal disorders. Prevalence, sociodemography, and health impact. Dig Dis Sci 1993;38:1569-1580.

28. Talley NJ, Phillips SF, Melton LJ, Mulvihill C, Wiltgen C, Zinsmeister AR. Diagnostic value of the Manning criteria in irritable bowel syndrome. Gut 1990;31:77-81.

29. Horwitz BJ, Fisher RS. The irritable bowel syndrome. N Engl J Med 2001;344:1846-1850.

30. Thompson WG, Irvine EJ, Pare P, Ferrazzi S, Rance L. Functional gastrointestinal disorders in Canada: first population-based survey using Rome II criteria with suggestions for improving the questionnaire. Dig Dis Sci 2002; 47:225-235.

31. Kay L, Jorgensen T, Lanng C. Irritable bowel syndrome: which definitions are consistent? J Intern Med 1998;244:489-494.

32. Talley NJ, Holtmann G, Agreus L, Jones M. Gastrointestinal symptoms and subjects cluster into distinct upper and lower groupings in the community: a four nations study. Am J Gastroenterol 2000;95:1439-1447.

33. Hahn BA, Saunders WB, Maier WC. Differences between individuals with self-reported irritable bowel syndrome (IBS) and IBS-like symptoms. Dig Dis Sci 1997;42:2585-2590.

34. Talley NJ, Gabriel SE, Harmsen WS, Zinsmeister AR, Evans RW. Medical costs in community subjects with irritable bowel syndrome. Gastroenterology 1995;109:1736-1741.

35. El-Serag HB. Impact of irritable bowel syndrome: prevalence and effect on health-related quality of life. Rev Gastroenterol Disord 2003;3 Suppl 2:S3-11.

36. Videlock EJ, Chang L. Irritable bowel syndrome: current approach to symptoms, evaluation, and treatment. Gastroenterol Clin North Am 2007;36:665-685. 
37. Cash BD, Schoenfeld P, Chey WD. The utility of diagnostic tests in irritable bowel syndrome patients: a systematic review. Am J Gastroenterol 2002;97:2812-2819.

\section{Author Affiliations}

Steven H. Yale, MD

Department of Internal Medicine

Marshfield Clinic

1000 North Oak Avenue

Marshfield, Wisconsin 54449

and

Clinical Research Center

Marshfield Clinic Research Foundation

1000 North Oak Avenue

Marshfield, Wisconsin 54449

A. Kenneth Musana, MD

Department of Internal Medicine

Marshfield Clinic

1000 North Oak Avenue

Marshfield, Wisconsin 54449

Amy Kieke, PhD

Epidemiology Research Center

Marshfield Clinic Research Foundation

1000 North Oak Avenue

Marshfield, Wisconsin 54449

Jennifer Hayes, MS

Clinical Research Center

Marshfield Clinic Research Foundation

1000 North Oak Avenue

Marshfield, Wisconsin 54449

Ingrid Glurich, PhD

Clinical Research Center

Marshfield Clinic Research Foundation

1000 North Oak Avenue

Marshfield, Wisconsin 54449

Po-Huang Chyou, PhD

Biomedical Informatics Research Center

Marshfield Clinic Research Foundation

1000 North Oak Avenue

Marshfield, Wisconsin 54449 